
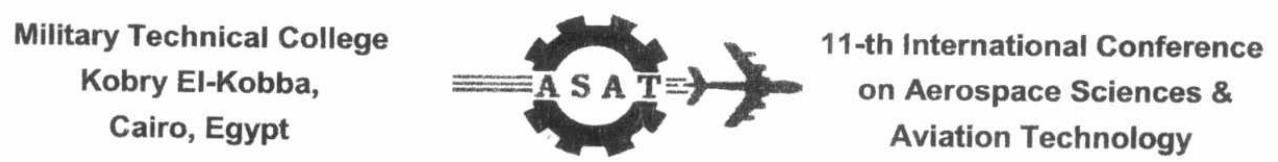

\title{
Assessment of Earth Remote Sensing Microsatellite Power Subsystem Capability during Detumbling and Nominal Modes
}

\author{
M. Zahran ${ }^{1,2}$ M. Okasha ${ }^{1}$ and Galina A. Ivanova ${ }^{3}$
}

1. National Authority for Remote Sensing and Space Science, Cairo Egypt, emailokasha77@hotmail.com

2. Electronics Research Institute, NRC Blg., El-Tahrir St., Dokki, 12311-Giza, EGYPT, Tel./Fax. 00202(3310512/3351631), Zahran@eri.sci.eg \& zahranmba@yahoo.com

3. Yuzhnoye State Design Office, 3, Kryvorozhzkaya st., Dniepropetrovsk Ukraine, 49008,Fax 38(056)770-04-30.

\begin{abstract}
The Electric Power Subsystem (EPS) is one of the most critical system on any satellite because nearly every other subsystem requires power. This makes the choice of power systems the most important task facing satellite designers. The main purpose of the Satellite EPS is to provide continuous, regulated and conditioned power to all the satellite subsystems. It has to do that withstanding the radiation, thermal cycling, and vacuum of a hostile space environment as well as the subsystem degradation over the time [1]. The EPS power characteristics are determined by both the parameters of the system itself and by the satellite orbit [2]

After the satellite separates from the launch vehicle (LV) to its orbit, in almost situations, all the satellite subsystems (attitude determination and control, communication, and onboard computer and data handling (OBC\&DH)), take their needed power from a storage battery (SB) and solar arrays (SA) beside the consumed power in EPS management device. But at this point (separation point, arrays with rede), the satellite angular motion is high and the orientation of solar arrays with respect to the sun will change in a non-uniform way, so the amount of power generated by solar arrays will be affected. The objective of this research is to select the satellite EPS components, types; estimation the solar arrays illumination parameters and determination of the efficiency of solar arrays during both detumbling
and nominal modes.
\end{abstract}

\section{Keywords:}

Earth Remote Sensing, EPS System Design, GaAs, NiCd, LEO, Orbit and Attitude Dynamics, Detumbling mode, DET, Orbit lllumination, Energy Management, and
Control. 


\section{Introduction}

During mission analysis, it is important to determine the total required power for nominal and off-nominal operations of satellite subsystems during different modes of operations, which in turn will play a great role in selection of a suitable battery and sizing of the solar arrays.

Most satellites use storage batteries like $\mathrm{NiCd}$ or $\mathrm{NiH}_{2}$ to store excess energy generated by the solar arrays during periods of exposure to the sun. During eclipse, the batteries are used to provide power for the satellite subsystems. The batteries are recharged when the satellite exits the eclipse [3]. The data of interest to EPS designers are orbit altitude, orbit inclination, the local time of ascending node, power budget (average and peak), and lifetime. These parameters have an influence on the following:

- The power generated by SA.

- The temperature of the effective area of the SA.

- The depth and the duration of the temperature cycles,

- The level of damage to the satellite equipment due to the Earth radiation

- The number and depth of the charge and discharge cycles of the SB.

The size of the microsatellite EPS components depends strongly on the orbital parameters and the power budget of the satellite onboard equipment that represented by the load profile that is a graphical representation of the power requirements of the satellite loads with time. The satellite orbital parameters that affecting the EPS operation are simulated during the lifetime to estimate the illumination coefficient of the EPS solar array taking into consideration the space environment and orbital perturbation. The most critical period of the satellite EPS operation starts from the satellite separation from launch vehicles till reaching the steady state (oriented) operation. In this period the satellite onboard equipment depends strongly on the storage battery since the output power from solar array is much lower than nominal.

When the satellite separates from the launch vehicle, it separates with high angular velocities. So, its attitude changes quickly, a control algorithm used to suppress these angular velocities and to construct an attitude. During this stage (detumbling mode) the attitude of the solar arrays relative to the sun will also change rapidly and the efficiency of charging and discharging the chemical battery will be affected much more during that stage. The power generated by the solar arrays is mainly depend on the angle between the direction to the Sun and the normal to its surface. To calculate this angle, a mathematical model will be built to simulate the satellite in its orbit to determine solar arrays attitude with respect to the sun. To do that a mathematical model of satellite orbital/attitude motion beside the sun motion will be developed, also a control algorithm will be selected to suppress the satellite angular motion and counteract the environmental disturbances.

\section{Basic of the EPS type selection}

The optimum choice of EPS components is not usually an easy task for the satellite designers due to the closed interaction between EPS and the dedicated mission of 
the satellite. The designers must be aware of the various power subsystems available on the satellite. Figure 1 shows the most suitable power sources on board average study is five years lifetimete sensing microsatellite, Sun synchronous orbit with a planned conclude that the most conclude that the most suitable primary source for the proposed satellite is the
photovoltaic (solar arrays).

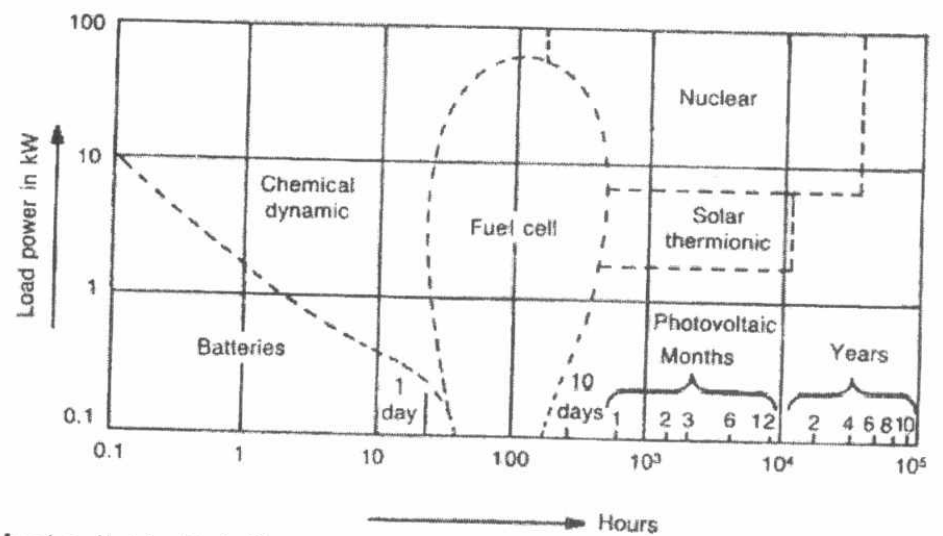

Fig. 1, Most suitable Satellite EPS components as a function of mission duration [3].

\subsection{Solar Array Type Estimation}

Several proven solar arrays technologies compete for the satellite market. These are single crystal Si solar cells, thin crystalline Si cells, GaAs solar cells, InP solar cells, and the cascaded solar cells. Table 1 summarizes the important characteristics of each technology [3]

Table 1, Summary of solar cell technologies for space applications

\begin{tabular}{|l|c|c|c|c|c|}
\hline & Crystalline Si & Thin Si cells & GaAs & InP & Cascaded \\
\hline Cell efficiency \% & 22 & 17 & 23 & 19 & 30 \\
\hline Array efficiency \% & $10-15$ & 8 & $19-21$ & & 17 \\
\hline Specific mass & 0.42 & & 0.36 & & \\
\hline Lifetime and reliability & Acceptable & Low & High & High & High \\
\hline Radiation tolerance: & & & & & \\
$1 \mathrm{MeV}$ electrons & 10 & & 33 & 155 & \\
$10 \mathrm{MeV}$ protons & 2 & & 6 & 89 & \\
\hline
\end{tabular}

It should be noted that the conversion efficiency of relevance to the system design is the array efficiency, rather than the cell efficiency. Array efficiencies are significantly lower than the cell efficiencies mainly because the former reports minimum guaranteed array efficiencies under factory conditions, whereas the latter reports 
record (maximum) values under laboratory conditions. GaAs solar arrays compared to Si solar arrays offer good combination of high efficiency and high radiation resistance; the two, most important metrics for space solar cells

In spite of their performance advantages, the InP and the cascaded solar cell technologies for space applications are still in the embryonic stage. The industrial base for these technologies is quite limited. Also, their radiation resistance data is quite scarce. Cascaded solar cell technologies include mechanically stacked cells, and monolithically cascaded cells. In the latter category, GaAs/Ge cells and InP/Si cells may be mentioned. In our proposal, the uni-junction GaAs/Ge solar arrays are used. Figure 2 presents the trends in space solar cell development and Figure 3 shows the I-V characteristics of GaAs/Ge solar cells

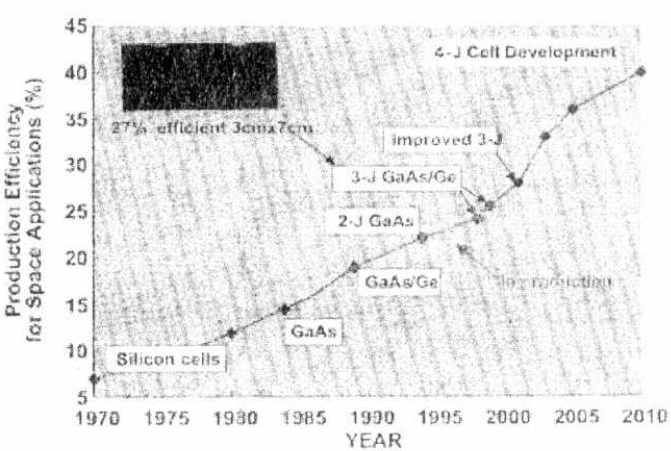

Fig. 2, Trends in space solar cell Development [4]

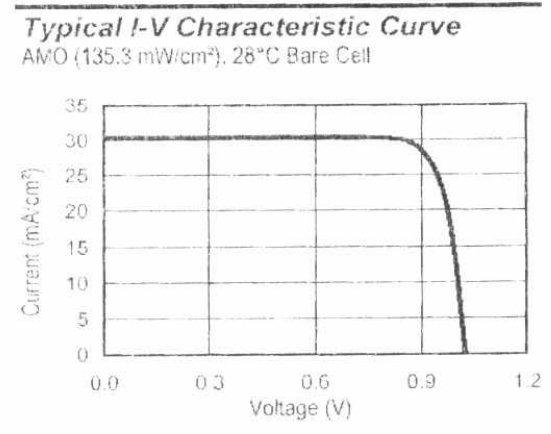

Fig. 3, GaAs/Ge Solar Cells I-V curve [5].

\subsection{Storage Battery Type Estimation}

Storage battery provides OBE with electrical power during satellite orbital flight (shadow segment and when power consumption of the load exceeds the power generated from SA) and also during ground satellite tests.

The satellite loads and the mission eclipse profile define the requirements for the battery design. The battery must provide a low-impedance bus voltage in the specified range of $28.0 \pm 6.0 \mathrm{~V}$ to power the OBE during eclipse and to handle any loads that exceed solar array capability. The battery sizing is driven by resultant power demand, the duration of the power discharge, and the total number of discharge cycles required by the mission. The battery must be tolerant of the failure of a single cell in either an open or short-circuit condition. The battery design is also driven by restrictions of operating temperatures and temperature gradients. The selection of battery technology was reduced to two candidate chemistries, $\mathrm{NiH}_{2}$ cell technology and NiCd technology. Table 2 compares the main characteristics of both $\mathrm{NiCd}$ and $\mathrm{NiH}_{2}$ batteries [6] 
Table 2, Summary of $\mathrm{NiCd}$ and $\mathrm{NiH}_{2}$ battery parameters.

\begin{tabular}{|c|c|c|c|c|c|c|}
\hline $\begin{array}{c}\text { Battery } \\
\text { type }\end{array}$ & Energy density & Mass & Volume & $\begin{array}{c}\text { Round } \\
\text { efficiency. }\end{array}$ & $\begin{array}{c}\text { Range of } \\
\text { temp. }\end{array}$ & $\begin{array}{c}\text { No of } \\
\text { cycles }\end{array}$ \\
\hline $\mathrm{NiCd}$ & $\begin{array}{c}30 \text { to } 40 \mathrm{WH} / \mathrm{kg} \\
\text { At battery level }\end{array}$ & Larger & Smaller & $\approx 80 \%$ & -5 to $+50^{\circ} \mathrm{C}$ & $2-8^{*} 10^{3}$ \\
\hline $\mathrm{NiH}_{2}$ & $\begin{array}{c}35 \text { to } 50 \mathrm{WH} / \mathrm{kg} \\
\text { At battery level }\end{array}$ & Smaller & Larger & $\approx 80 \%$ & -5 to $+50^{\circ} \mathrm{C}$ & $2-7^{*} 10^{3}$ \\
\hline
\end{tabular}

NiCd: it has the following advantages;

- Dependable and widely used technology for space missions.

- Provides high current with a rapid recharge capability. - High tolerance to overcharging and is capable of over 6000 recharge cycles at
$100 \%$ DOD, and

- Relatively low cost.

While it has two disadvantages;

- Prone to memory effect and Low cell voltage.

$\mathrm{NiH}_{2}$ : It is characterized by the following;

- It has more capacity than NiCd leading to fewer recharge cycles and No memory effect

While it has the following disadvantages;

- More heat generated during recharge than NiCd's. - Requires complex charging to prevent damage from overheating and
overcharge.

- Longer recharge times than NiCd.

The NiCd battery was chosen because of its safety record and because of its past success as a secondary power source. The charge/ discharge characteristics of NiCd are illustrated in Figure 4 [6].
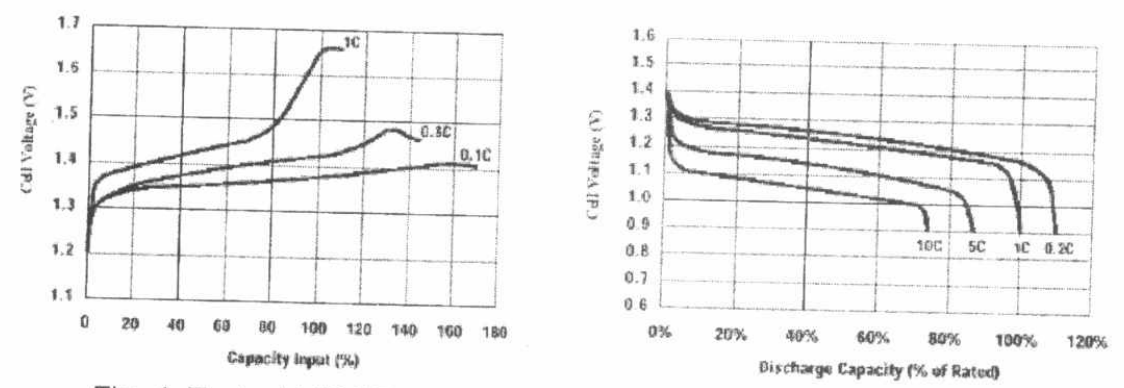

Fig. 4, Typical NiCd Battery charging/discharging curves at $23^{\circ} \mathrm{C}$

The discharge curve is fairly consistent through most of its discharge cycle and it can be recharged at $0.5 \mathrm{C}$ to virtually full capacity within the time allowed. Although the capacity of NiCd batteries may exhibit loss due to "memory effects", or more accurately Voltage depression, the degree to which this occurs can be minimized by varying the batteries' depth of discharge (DOD) during their life cycle. Depending on the duty cycle of some power intensive subsystems such as communications, more 
power will be drawn on some orbits than on others. This will provide the battery with a varying DOD and should result in acceptable capacity during the satellite lifetime period.

\section{Orbit selection}

The orbit selection is strictly dictated by the requirements of the remote sensing payload. It must be ensured that the chosen orbit is technically feasible, bearing in mind the availability of various launch vehicles. It is convenient to divide the selection of a suitable orbit into two steps. Since the remote sensing user is invariably interested in comparing data from spatially distinct regions, it is important that all data are collected from the same satellite altitude, so that all features on the ground appears on the same scale. This is achieved with a circular orbit around the earth. low earth orbit is the generic term given to circular orbits with the altitude between 300 and $1500 \mathrm{~km}$. Such orbits are predominantly used manned spacecraft and most remote sensing satellites. Being much closer to Earth greatly enhanced spatial and radiometric resolutions can be attained. To avoid the risk of premature recently and to limit as much as possible significant orbit decay, the satellite should be placed in an orbit of at least $600 \mathrm{~km}$ [7].

The proposed satellite is Sun synchronous with local time of passing the ascending node 10 hours and 30 minutes. The altitude of the circular orbit is $\sim 670 \mathrm{~km}$, inclination $\sim 98^{\circ}$, period of satellite orbit $\sim 100 \mathrm{~min}$, approximately like the orbit of satellite in [1].

For the orbits of such type small variation of the orbit illumination portions by the Sun and the Earth shadowing section in a revolutions during the whole flight active lifetime. In the following sections an analysis of the orbit illumination pattern as well as solar array output power is introduced.

\section{EPS Configuration and Block Diagram}

The EPS includes solar arrays, storage batteries and management and control devices, that estimates the appropriate mode of system operation and forms the control signals and sends/receives the control commands and TM data exchanges.

The two major approaches for satellite EPS configuration design are; direct energy transfer (DET) and maximum power point tracking (MPPT) [8]. In DET method, the payload, subsystems and batteries are directly connected to the solar arrays and the extra power (at low temperatures and/or Beginning Of Life (BOL)) are absorbed (consumed) by shunt regulators while in the MPPT additional mechanisms and control devices are needed to track the sun during operation. Because of the reliability parameter, the first proposal (DET) is applied.

The management and controller unit must control the excess solar array power that is not used for the loads or for battery recharge. It must monitor and maintain the health of the battery by optimizing the battery charge rate during battery refill after all battery discharges. It must prevent damage to the battery and satellite loads by protecting against an over-voltage or under-voltage condition of the power bus. Finally, it must interface with the satellite $O B C \& D H$ subsystem, providing EPS telemetry and receiving ground commands [6], [9].

The management and coritroller unit controls the charge/discharge process of the storage battery by controlling the output power from solar array and protect the 

battery from deep discharging in the undesired or overloading sessions. Figure 5
shows the EPS block diagram based on DET configuration.

The size of solar array could be estimated by the help of the value of OBE loading (average power budget) and the specific output power of solar array. Also the size of the storage battery capacity depends on the needed amount of OBE energy during shadowing and eclipse period.

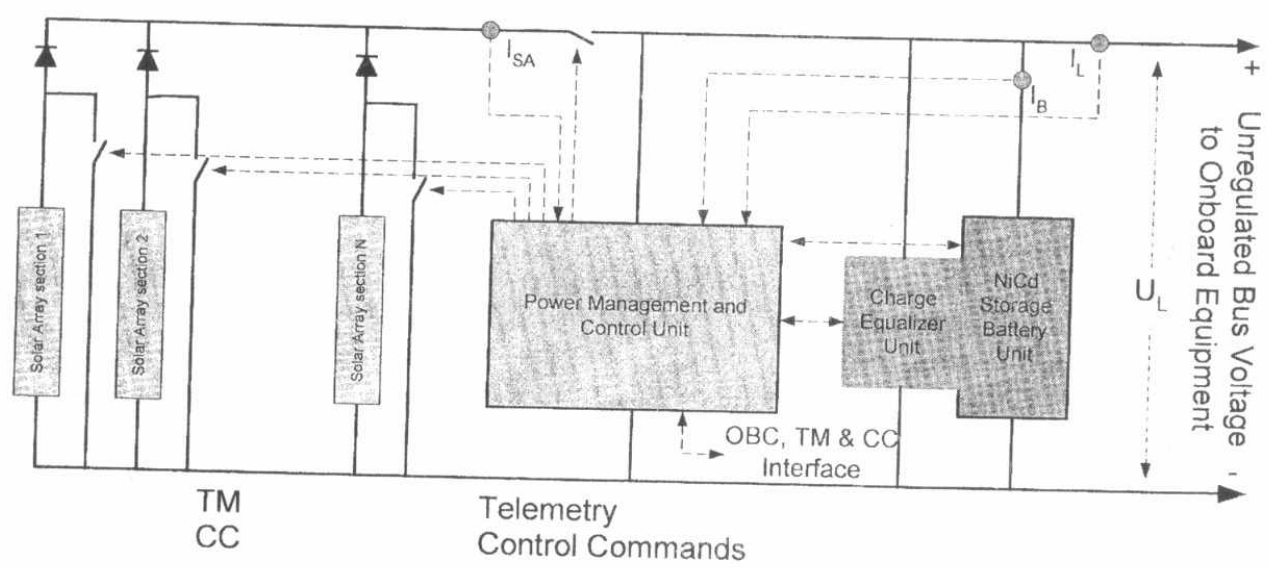

Fig. 5, Proposed microsatellite EPS block diagram.

\section{Estimation of the specific output power from SA of the EPS}

The specific output power from the EPS solar array (SA) depends on the type of SA air mass zero (AMO) parameters, orbit parameters type, altitude and inclination of the orbit. The orientation of the solar arrays affects strongly the generated output power. From the energy balance point of view, the amount of average power that must be produced by the solar arrays, $P_{\text {sa }}$ could be expressed as $[3,10-11]$ :

Where:

$$
P_{s a}=\left\{\left(P_{e} * T_{e} / X_{e}\right)+\left(P_{d} * T_{d} / X_{d}\right)\right\} / T_{d}
$$

$$
\begin{array}{ll}
\mathrm{P}_{\mathrm{e}} \text { and } \mathrm{P}_{\mathrm{d}} & \begin{array}{l}
\text { are the power requirements during eclipse and daylight (power } \\
\text { budget), }
\end{array} \\
\mathrm{X}_{\mathrm{e}} \text { and } \mathrm{X}_{d} & \begin{array}{l}
\text { are the efficiencies of the paths from the arrays to the batteries } \\
\text { and the loads, }
\end{array} \\
\mathrm{T}_{\mathrm{e}} \text { and } \mathrm{T}_{\mathrm{d}} & \text { are the times in eclipse and daylight. }
\end{array}
$$
The specific output power from solar arrays at the terminals of the OBE could be
expressed as follows:

$$
\begin{aligned}
& \text { Where } P_{S A}\left(W / m^{2}\right)=P_{n}^{*} F F * K_{i l l} * K_{t h} * K_{m p p d} * \eta_{s y y} * K_{d} \\
& \quad P_{n} \text { is the output power at begins of life; } \\
& \qquad \begin{aligned}
P_{n} \quad=A M 0\left(1358 \mathrm{~W} / \mathrm{m}^{2}\right) * \eta_{S A}(\sim 0.2) \\
F F \quad \text { is the filling factor of the solar array module; } \sim 0.85,
\end{aligned}
\end{aligned}
$$


$\mathrm{K}_{\mathrm{ill}} \quad$ is the solar array surface illumination coefficient,

$\mathrm{K}_{\mathrm{th}}$ is the thermal coefficient of solar array,

$K_{\text {mppd }}$ is the matching factor between SA MPP and OBE loading, (0.9-1.0),

$\eta_{\text {sys }}$ is the energy transmission efficiency; $\sim 0.87$,

$\mathrm{K}_{d} \quad$ is the GaAs solar array degradation parameter; $\sim 0.9$

By estimating the specific output power from solar arrays and substituting by the obtained results of $\mathrm{P}_{\mathrm{sa}}$, the needed area of solar arrays could be estimated.

\section{Estimation of the illumination and thermal coefficients}

The illumination and thermal parameter depends on the satellite orbit analysis during the lifetime of the satellite. In the following an analysis is done for the orbit/attitude dynamics.

\subsection{Coordinate Systems}

Through the development of mathematical model the following orthogonal coordinate systems are used:

- Inertial coordinate system (ICS) $\left(\mathrm{O}_{\mathrm{e}} \mathrm{X}_{\mathrm{i}} \mathrm{Y}_{\mathrm{Z}} \mathrm{Z}_{i}\right)$ : $\mathrm{O}_{\mathrm{e}}$ origin coincides with the Earth center; axis $\mathrm{O}_{e} Y_{i}$ is directed along the Earth axis of rotation; axis $\mathrm{O}_{e} Z_{i}$ is directed to the vernal equinox; axis $\mathrm{O}_{e} \mathrm{X}_{i}$ complete the right hand side and lie on the equatorial plane.

- Sun ecliptic coordinate system (SECS) $\left(\mathrm{O}_{e} X_{s} Y_{s} Z_{s}\right): O_{e} Z_{s}$ axis is directed along Earth-Sun vector; $\mathrm{O}_{\mathrm{e}} \mathrm{Y}_{\mathrm{s}}$ axis is along the normal to the ecliptic; $\mathrm{O}_{\mathrm{e}} \mathrm{X}_{\mathrm{s}}$ axis complete the right hand side and directed to the Sun motion along the ecliptic.

- Orbital coordinate system (OCS) $\left(\mathrm{O}_{b} \mathrm{X}_{0} \mathrm{Y}_{0} \mathrm{Z}_{0}\right)$ : $\mathrm{O}_{\mathrm{b}}$ origin coincides with the SC $\mathrm{COM} ; \mathrm{O}_{\mathrm{b}} \mathrm{Z}_{0}$ axis is directed along the radius vector that connect the center of Earth to the SC COM; $\mathrm{O}_{b} X_{0}$ axis is in the direction of flight

- Design coordinate system (DCS) $\left(O_{d} X_{d} Y_{d} Z_{d}\right): O_{d}$ origin is in SC-LV interface plane; axis $\mathrm{O}_{d} Z_{d}$ axis is perpendicular to the SC-LV interface plane and is directed to the $L V ; O_{d} X_{d}$ and $O_{d} Y_{d}$ axes lie in the plane of mating

- Body axes system (BAS) $\left(\mathrm{O}_{b} \mathrm{X}_{b} \mathrm{Y}_{b} Z_{b}\right)$ : the body axes are parallel and co directional to the DCS axes; in the case of ideally oriented satellite the body axes coincide with the OCS axes. 


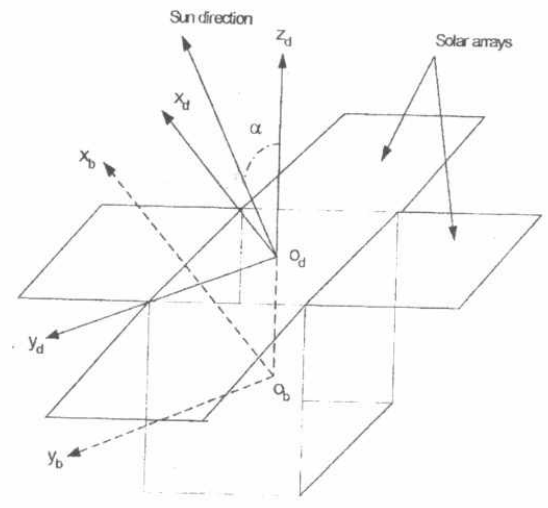

Fig. 6, Satellite layout

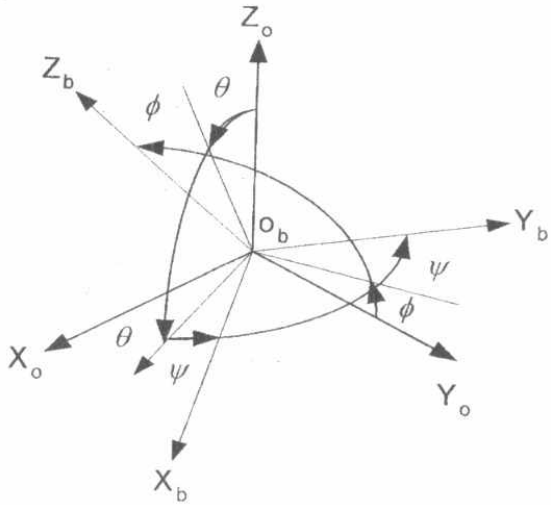

Fig. 7, Coordinate systems

Fig. 6 shows the satellite layout, orientation of solar arrays with respect to the Sun (angle $\alpha$ ) and the body and design coordinate system, while Fig. 7 shows the orientation of body with respect to orbit coordinate system as a sequence of rotation $(\theta, \varphi$, and $\psi)$.

\subsection{Orbit Dynamics}

The orbit dynamics describe the translation motion (position and velocity) of a body (satellite or planet) orbiting another body. The satellite orbit and Sun orbit is propagated by the orbit generator given in Vallado [12].

$$
\vec{r} \cdot \ddot{=}=-\frac{\mu}{r^{3}} \vec{r}+\bar{a}_{p}
$$

Where: $\vec{a}_{p}$ is the vector of accelerations due to disturbances (gravity, aerodynamics solar radiation ...etc),

$\ddot{r} \quad$ is position vector of satellite in inertial coordinate system. In modeling, two forces will be taken into account, gravity force and aerodynamic
drag.

\subsection{Attitude Dynamics and Kinematics}

Attitude is used to describe the orientation of one reference coordinate to another reference coordinate, such as a satellite body coordinate with respect to an inertial coordinates dynamic equations of motion on BAS are as follow $[13,14]$

Where:

$$
\omega_{b i}^{* b}=\left(J^{b}\right)^{-1} \cdot\left(\bar{M}_{s}^{b}+\bar{M}_{c i r l}^{b}-\omega_{b i}^{b} \times\left(J^{b} \cdot \omega_{b i}^{b}+H^{b}\right)\right)
$$

$$
\begin{array}{ll}
J^{b} & \text { is the satellite inertia, } \\
\bar{M}_{s}^{b} & \text { is the sum vector of disturbance moments }
\end{array}
$$



$\vec{M}_{c|r|}^{b}$
is vector of control moment
$\omega_{b i}^{b}, \omega_{b i}^{\cdot b}$ are SC absolute angular velocity and acceleration respectively, $H^{b}$ is the angular momentum of the wheel.

The SC kinematics equation of motion around COM in Quaternion form will be:

$$
Q \cdot=\frac{1}{2} \cdot Q \cdot \omega_{b o}^{b}
$$

Where:

$$
\begin{aligned}
& Q^{\bullet} \quad=q_{0}^{\cdot}+q_{1}^{\bullet}+q_{2}^{\cdot}+q_{3}^{*} \text { is the derivative of Quaternion vector } \mathrm{Q}, \\
& \omega_{b o}^{b} \quad \text { SC angular velocity relative to OCS projected on BAS. }
\end{aligned}
$$

For a Sun synchronous LEO with $\sim 670 \mathrm{~km}$ altitude and $\sim 98^{\circ}$ orbital inclination, a developed software program is developed in MATLAB to simulate the changes in angle to normal of solar array plan and Sun direction, eclipse time and local time of ascending. The illumination coefficient is calculated taking into consideration the orbital perturbations and satellite separation from launch vehicle accuracy. A sample of the developed program results is illustrated in figure 8 . The results show; the angie between the normal to orbit plane and Sun direction (Nue) in degree, the orbit Earth shadowing (TS) in min, current of SAs, Load and battery capacity $\left(I_{S A}, I_{\llcorner} \& Q_{S B}\right)$ as well as storage battery $(\mathrm{SB})$ voltage and temperature $\left(\mathrm{V}_{\mathrm{SB}} \& \mathrm{~T}_{\mathrm{SB}}\right)$.

The results are illustrated in figure 8 , since the range of illumination parameter is found as $(0.2438-0.295$; average $\sim 0.265)$. Also by analyzing the thermal parameter of the solar array, it is found that it is $\sim 0.9025$ for GaAs solar arrays for the specified orbit altitude.

So, the specific output power from the GaAs solar array could be estimated as follows:

$$
\begin{aligned}
& P_{S A}\left(W / m^{2}\right)_{G G A-B O I-\text { max }} \quad=K_{\text {sysiem }} * K_{\text {lll } \max } \\
& =54.4 \mathrm{~W} / \mathrm{m}^{2} \\
& P_{S A}\left(W / m^{2}\right)_{\text {GaAs-EOl-min }} \quad=K_{s: m e m} * K_{d} * K_{i l l \text {-nin }} \\
& =39.8 \mathrm{~W} / \mathrm{m}^{2}
\end{aligned}
$$

The maximum output power at begins of life and best illumination coefficient is estimated as $87 \mathrm{~W}$ while the power at end of life and worst illumination is found as $63.5 \mathrm{~W}$. The average output power from solar array at BOL could be estimated as follows:

$$
\begin{aligned}
P_{S A}(W)_{\text {GaAs - BOL-av }} & =K_{s y s t e m} * A_{s a} * K_{i l l-a v} \\
& =76.9 \mathrm{~W}
\end{aligned}
$$




\section{EPS Capability during Detumbling Mode}

To estimate the capability of EPS during the detumbling mode, the disturbance and control moments of the microsatellite should be studied.

\subsection{Disturbances and Control Moments}

Satellite in orbit encounter small disturbance moments from various environmental sources. These moments are either secular, which accumulate over time, or cyclic, which vary sinusoidal over an orbit. Both types are discussed by $[13,14]$.

Different environmental moments are more prevalent at different altitudes. In low and aerodynamic. In this paper aerodynamic moments ars paper, gravity-gradient, magnetic, solar radiation and Usually, in detumbling are considered.

Usually, in detumbling mode magnetorquers are used for creation of control moment. It produces the control moments by means of the interaction its magnetic moment with the terrestrial magnetic field [14].
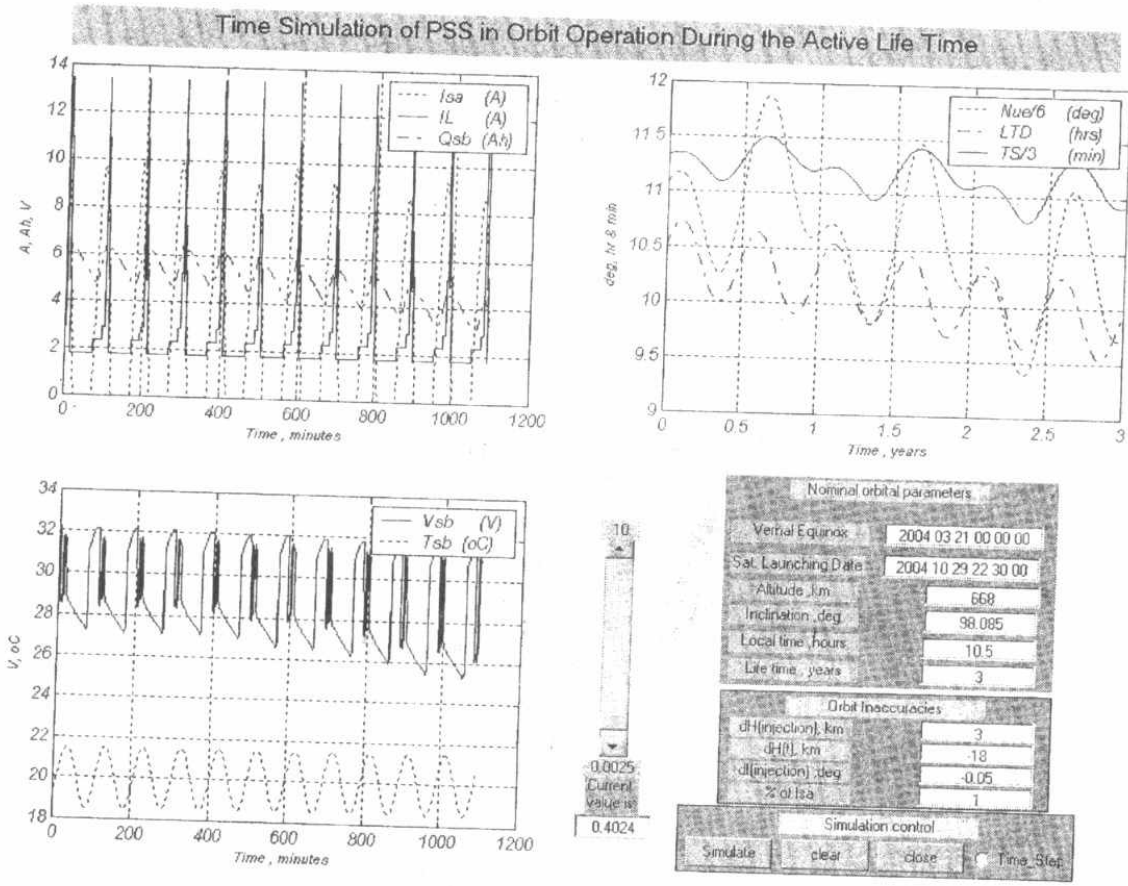

Fig. 8, A sample of the developed program results. 


\subsection{Numerical Example}

To demonstrate the effective power generated from the solar arrays during detumbling mode the following numerical example has been performed.

The mentioned above Sun synchronous, low Earth orbit (LEO) is considered in this simulation. The satellite is assumed to have moment of inertia

$$
J=\left[\begin{array}{ccc}
16 & 0 & 0 \\
0 & 16.7 & 0 \\
0 & 0 & 14
\end{array}\right]{\mathrm{kg} . \mathrm{m}^{2}}^{2}
$$

MATLAB software package used to integrate (simulate) system of equations $(3,4,5)$ and the angle $\alpha$ (angle between the Sun and normal to solar arrays as shown in Fig. 6 ) is determined.

Fig. 9 shows the variation in angle a for 500 minutes after separation from the LV, it is noted that during the first 100 minutes, this angle changes quickly as expected (because of the satellite separates from the LV with high angular velocity) but after the angular velocity suppressed, the variation becomes uniform, that appears in the last 200 minutes.

Three different cases were studied each case related to different initial conditions of attitude (angles and angular velocities at separation point). Table 3 shows the value of the illumination coefficient (average cosine of the angie $\alpha$ ) that indicate the specific power generated from the solar arrays, as this coefficient increase the specific power increase.

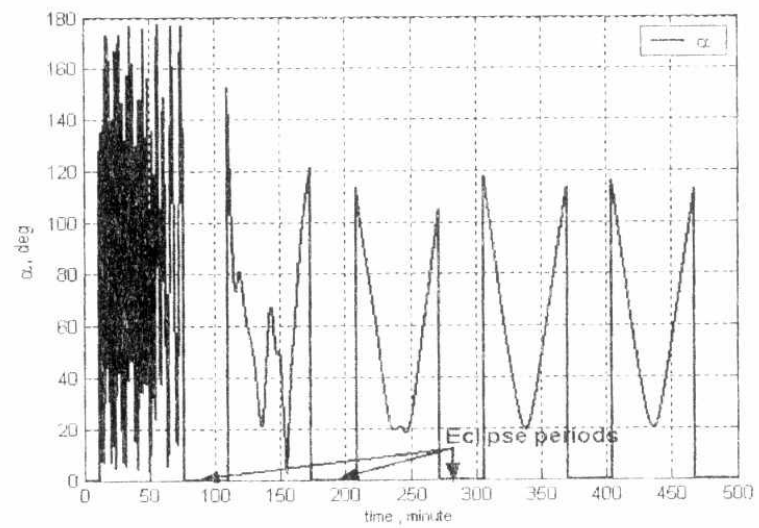

Fig. 9, Angle between the Sun and normal to solar arrays (Case1)

Table 3. Average lilumination coefficient ( $\sum \cos (\alpha) / 100$ min period of time)

\begin{tabular}{|cccccc|}
\hline $\begin{array}{c}\text { Time, } \\
\text { minutes }\end{array}$ & $0-100$ & $100-200$ & $200-300$ & $300-400$ & $400-500$ \\
\hline Case 1 & 0.1844 & 0.3003 & 0.3455 & 0.2957 & 0.2982 \\
Case 2 & 0.1879 & 0.2768 & 0.2957 & 0.2986 & 0.2967 \\
Case 3 & 0.1663 & 0.3923 & 0.2906 & 0.2960 & 0.2975
\end{tabular}




\section{Calculation of the available energy from EPS during detumbling mode}

In the following, Table 4 shows the calculation of the available energy during detumbling and for a two other successive steady state modes.

Table 4, EPS available energy during detumbling mode calculation.

\begin{tabular}{|c|c|c|c|c|c|c|c|c|c|c|}
\hline $\begin{array}{r}\text { Period } \\
\mathrm{min}\end{array}$ & Kill & $\begin{array}{c}\text { Power } \\
100\end{array}$ & \begin{tabular}{|c|c|} 
Kill \\
$100-$ \\
200
\end{tabular} & $\begin{array}{c}\text { Power } \\
200\end{array}$ & \begin{tabular}{|c|} 
Kill \\
$200-$ \\
300 \\
\end{tabular} & $\begin{array}{c}\text { Power } \\
300\end{array}$ & \begin{tabular}{|c|c|} 
Kill & P \\
$300-$ & $P$ \\
400 & \\
\end{tabular} & $\begin{array}{c}\text { Power } \\
400\end{array}$ & \begin{tabular}{|c|c|} 
Kill & $\mathrm{Pc}$ \\
$400-$ & 5 \\
500 & 5 \\
\end{tabular} & $\begin{array}{c}\text { Power } \\
500 \\
\end{array}$ \\
\hline 1 & \begin{tabular}{|l|l|}
0.1844 & 4 \\
\end{tabular} & 48.10 & 0.30037 & 78.33 & 0.3455 & \begin{tabular}{|l|l|}
90.10 & 0 \\
\end{tabular} & $\begin{array}{ll}0.2957 & 7\end{array}$ & $77.10 \mathrm{C}$ & \begin{tabular}{l|l}
0.2982 & 77 \\
\end{tabular} & 77.80 \\
\hline 2 & 0.18794 & 49.00 & 0.27687 & 72.18 & 0.2957 & 77.130 & \begin{tabular}{|l|l}
0.2986 & 7 \\
\end{tabular} & 77.900 & $\begin{array}{lll}0.2967 & 77 \\
\end{array}$ & 77.37 \\
\hline 3 & \begin{tabular}{|l|l}
0.1663 & 4
\end{tabular} & $43.40] 0$ & \begin{tabular}{|l|l}
0.3923 & 1
\end{tabular} & 102.3 & 0.2906 & 75.78 & 0.29607 & $77.20 \mathrm{C}$ & \begin{tabular}{|l|l|}
0.2975 & 77 \\
\end{tabular} & 77.60 \\
\hline Average power $(W)$ & \begin{tabular}{|r|}
46.8 \\
\end{tabular} & & 84.27 & 27 & 81. & .0 & 77.4 & & 77.6 & \\
\hline $\begin{array}{l}\text { Average available energy } \\
\quad \text { from the } S A(W h)\end{array}$ & 78.0 & & 140. & 0.5 & 13 & 35 & 129 & & 129.3 & \\
\hline $\begin{array}{l}\text { Total available energy } \\
\text { from PSS at } 8 A h\end{array}$ & \multicolumn{5}{|c|}{$564.7 \mathrm{Wh}$} & \multirow{2}{*}{\multicolumn{5}{|c|}{$\begin{array}{l}\text { The needed amount of energy } \\
\text { for the satellite OBE during } \\
\text { detumbling mode (300min) can } \\
\text { be expressed as: }\end{array}$}} \\
\hline $\begin{array}{l}\text { DOD at needed amount } \\
\text { of energy } \%\end{array}$ & \multicolumn{5}{|c|}{$52.08 \%$} & & & & & \\
\hline $\begin{array}{c}\text { Total available energy } \\
\text { from PSS at } 7 A h\end{array}$ & \multicolumn{5}{|c|}{$538.3 W h$} & \multirow{3}{*}{$\begin{aligned} P_{\text {Sal }} & = \\
& + \\
& + \\
& *\end{aligned}$} & \multirow{4}{*}{\multicolumn{4}{|c|}{$\begin{array}{l}=\{\text { ADCS }(40 \mathrm{~W} \text { max }) \\
+P C D H S(41.5 W \text { max }) \\
+P S S(4 W)+G P S(4.2 W \text { max }) \\
\left.+C S \_S-B a n d(3 W a v)\right\} \\
+5 \text { hrs } \\
=463.5 \text { Whmax }\end{array}$}} \\
\hline $\begin{array}{l}\text { DOD at needed amount } \\
\text { of energy } \%\end{array}$ & \multicolumn{5}{|c|}{$59.52 \%$} & & & & & \\
\hline $\begin{array}{l}\text { Total available energy } \\
\text { from PSS at } 6 A h\end{array}$ & \multicolumn{5}{|c|}{$511.9 \mathrm{Wh}$} & & & & & \\
\hline $\begin{array}{c}\text { DOD at needed amount } \\
\text { of energy } \%\end{array}$ & \multicolumn{5}{|c|}{$69.44 \%$} & $P_{\text {Sat }}$ & & & & \\
\hline
\end{tabular}

It is noted that EPS has a positive energy balance in all cases of the SB capacities, and hence it is capable to provide the involved satellite OBE during detumbling mode

\section{Conclusion:}

The power subsystem type and its components characteristics are estimated and studied. The Earth remote sensing microsatellite power supply sizing is presented NiCd batterion is used. The GaAs solar cells and the dynamics and the used to build the EPS for the under build microsatellite. The orbit MATLAB based software program and kinematics are analysed by developing a during the active lifetime orbit and solar array illumination pattern orbit perturbations and the satellite in orbit operation taken into consideration the coefficient are found plan in orbital coordinate system $(0.2438-0.296)$ for a fixed solar arrays in a single output power are estimated in the maximum and minimum specific SA degradation of SA and its in the range $\left(39.8-54.4 \mathrm{~W} / \mathrm{m}^{2}\right)$ taken into consideration 
An algorithm for simulating and controlling the satellite attitude/orbit has been developed in order to determine the crientation of solar arrays with respect to the sun direction during nominal and detumbling modes of operations. The angle between the sun and the normal to solar arrays is computed and an estimation of the output power from the solar arrays is calculated. A numerical example based on a LEO sunsynchronous remote sensing satellite for demonstration the efficiency of the solar arrays during detumbling mode of operation.

The different conditions of the SB state of charge are considered and the EPS available energy is estimated also at each case. The energy balance results between the available EPS and the needed OBE amount of energy confirm that the EPS is capable to provide the involved satellite subsystems by the needed energy during detumbling mode and nominal modes of operation without any off-nominal situation.

\section{References}

1. TERMA A/S Space Division, "Fower Management and distribution Systems", www.terma.com.

2. D.G. Belov, et.al, "Electric Power Supply for Ocean Satellite", sixth European Space Power Conference, Porto, Portugal, 6-10 May 2002 (ESA SP -502, May 2002).

3. Wertz, J. and Larson, W., Eds., Space Mission Analysis and Design. Boston, Kluwer Academic Publishers, 1991

4. ManTech for Multi-Junction Solar Cells, http://www. afrl.af.mil/techconn/index.htm"

5. Spectrolab Inc. 12500 Gladstone Avenue, Sylmar, California 91342 USA, www. spectrolab.com.

6. Paul E. Panneton and Jason E. Jenkins, "The MSX Spacecraft Power Subsystem", Johns Hopkins APL. Technical Digest, Volume 17, Number 1 (1996)

7. S.R. Cvetkovic and G.J. Robertson, "Spacecraft Design Considerations for Small Satellite Remote Sensing", IEEE Transaction on Aerospace and Electronic Systems, Vol. 29, No. 2, April 1993

8. Masoum, Mohamed A.S. and Dehbonei, Hooman, "Design, Construction and Testing of a Voltage-based Maximum Power Point Tracker (VMPPT) for Small Satellite Power Supply", $13^{\text {th }}$ Annual AIAAVUSU Conference on Small Satellites, SSC99-XII-7, 1999

9. Andy Bradford, Luis M Gomes, Prof. Sir Martin Sweeting and Gokhan Yuksel, Cem Ozkaptan, Unsal Orlu, "BILSAT-1: A Low-Cost, AGILE, Eearth Observation Microsatellite for TURKEY", 53rd International Astronautical Congress October 2002/Houston, Texas

10. Greg Merritt and John Opiela, "Satellite Power Systems Sizing", www.tsgs utexas/tadp/1995/spects/power.

11. You zheng, Gong ke, "Tsinghua Micro/Nanosatellite research and it's application", 13th Annual AIAA/USU Conference on Small Satellites, SSC99-IX-3.

12. D. A. Vallado, Fundamentals of Astrodynamics and Applications. NY: McGraw-Hill, 1997.

13. Peter C. Hughes. Spacecraft Attitude Dynamics. John Wiley and Sons, New York, 1986.

14. James R. Wertz, editor. Spacecraft Attitude Determination and Control. Kluwer Academic Publishers, Dordrecht, 2000 